\title{
Application of Computed Tomography for measuring of roundness
}

\author{
Zastosowanie tomografii komputerowej \\ do pomiaru odchyłek okrągłości
}

\author{
BARTOSZ GAPIŃSKI \\ MICHAK WIECZOROWSKI \\ KAROL GROCHALSKI \\ KATARZYNA PETA*
}

Customer expectations in terms of products quality are constantly growing. Therefore, to control only dimensions is not enough; it is necessary to check also the form deviation or roughness. The vast majority of measurement nowadays is carried out by different coordinate measuring devices. Measuring computed tomography is the newest field of coordinate measuring technique, which makes many aspects of its accuracy and possible applications still open. The paper presents the measurement results of elements with different values of roundness deviations. Examined samples were checked on a formtester and computed tomography. For CT measurement, different strategies to verify the influence on received results were used. The ability to measure form deviations on CT allows to verify the quality of hard to reach part areas, but also a comprehensive assessment of geometry, e.g. parts made of plastic and measured on CT.

KEYWORDS: computed tomography, form deviation, coordinate measuring technique, measurement accuracy

Roundness deviations are among the most frequently controlled form deviations. Their form directly affects the ability and accuracy of the connection and cooperation of elements. Supervision of their form can be carried out using various reference and non-reference methods, and their selection depends on the uncertainty of measurement required $[1,2]$.

\section{Computed tomography}

In recent years, a new group of devices has appeared - computer tomographs. The possibilities of their use are very wide, also in the field of metrology of geometric quantities.

The result of the computer tomography scan is a series of X-rays of the examined object made from different positions relative to the common axis of rotation. The spatial image of measured object is obtained as a result of computer reconstruction [3-5]. It contains

*PhD Eng. Bartosz Gapiński (bartosz.gapinski@put.poznan.pl), Prof. Eng Michał Wieczorowski (michal.wieczorowski @put.poznan.pl), MSc Eng Karol Grochalski (karol.p.grochalski@doctorate.put.poznan.pl), MSc Eng Katarzyna Peta (katarzyna.peta@put.poznan.pl) - Institute of Mechanical Technology, Faculty of Mechanical Engineering and Management, Poznan University of Technology information on both the surface limiting element and its internal structure, i.e. porosity, fiber structure and wall thickness.

Computed tomography (CT) is known in medicine since the 1970s. However, only the devices proposed around 2005 allow to obtain the accuracy adequate to the requirements for parts in the machine construction [6, 7].

\section{Tested object}

The aluminum sleeve with an outer diameter of $80 \mathrm{~mm}$ and an inner diameter of $74 \mathrm{~mm}$ was tested. The sleeve was specially modified to obtain different forms and values of roundness deviation in different cross-sections.

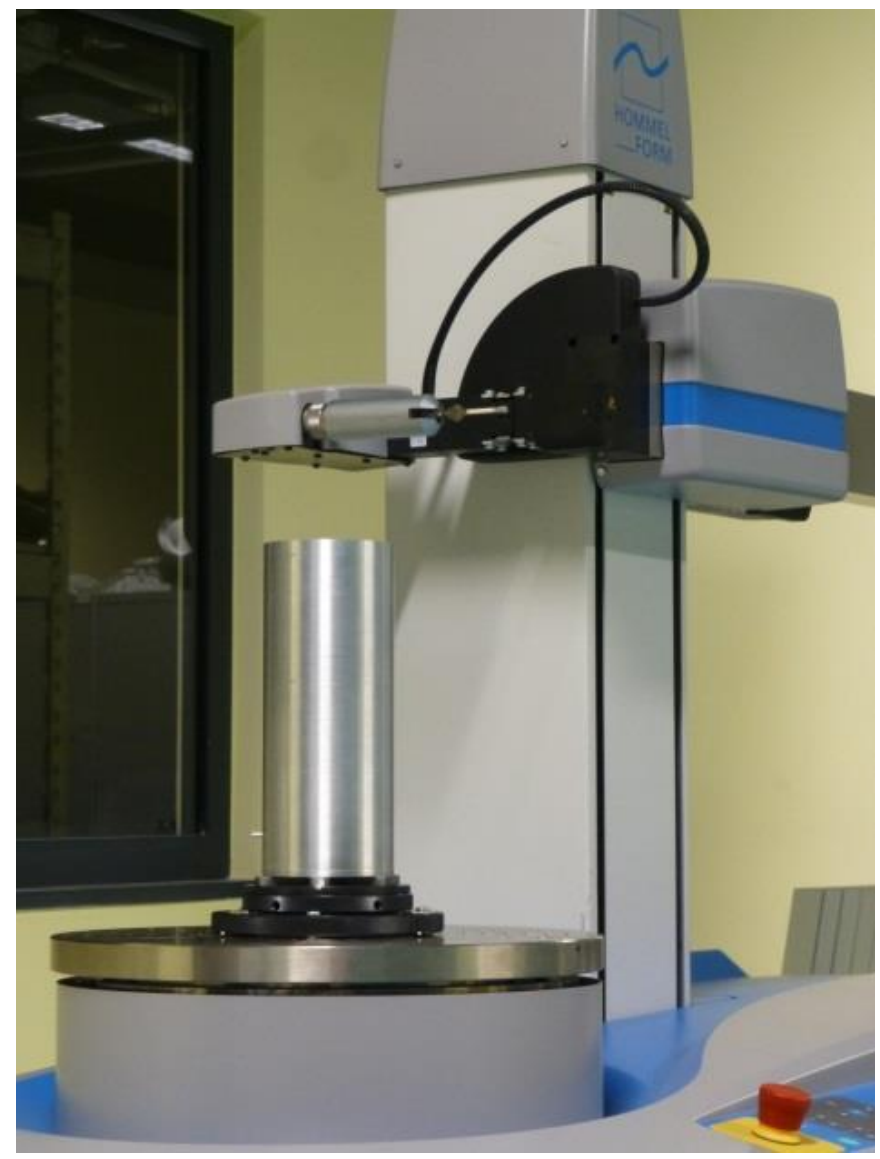

Fig. 1. Jenoptik Hommel Roundscan 535 formtester with measured sleeve (PUT laboratory) 
a)

b)
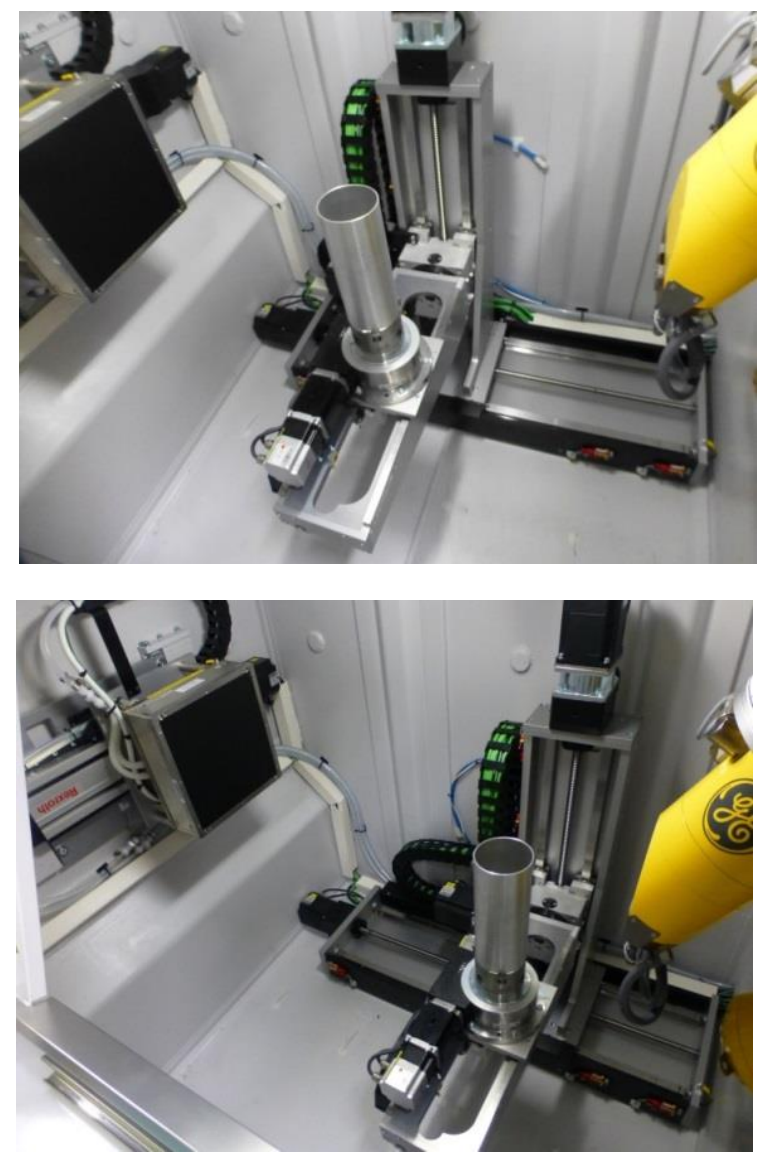

Fig. 2. Sleeve during measurement on the GE Phoenix v|tome|x s240 tomograph: a) onefold detector - the object away from the radiation source, b) motion of the detector (twofold detector) providing double image enlargement - the object closer to the X-ray tube

The tests were carried out on a Jenoptik Hommel Roundscan 535 formtester (fig. 1) and a GE Phoenix v|tome|x s240 computer tomograph (fig. 2). Two measurement strategies were used for the tomograph with single and double measurement ranges. In the first case (fig. 2a), onefold detector means that detector is stationary during the measurement. This allowed a $2.3 \times$ magnification at the $87.5 \mu \mathrm{m}$ voxel size. In the second case (fig. 2b), twofold detector mode gives the possibility of doubling the measuring range using motion of the detector. This allows to obtain an image with twice the magnification (4.6x) and twice the size of the smaller 43 $\mu \mathrm{m}$ voxel.

\section{Test results}

Examination and evaluation of the roundness deviation was carried out in three cross-sections of the sleeve, $(10,40$ and $80 \mathrm{~mm})$, placed from the top of the sleeve. In each case, the profile was analyzed independently for the external and internal contours.

Fig. 3 shows exemplary results for the outer crosssection, while fig. 4 - for the inner, located $80 \mathrm{~mm}$ from the top of the sleeve. Images of individual cross-sections and the assembly of obtained profiles indicate their significant correlation. In both cases, the differences between profiles do not exceed $10 \mu \mathrm{m}$ for all three measuring methods. a)
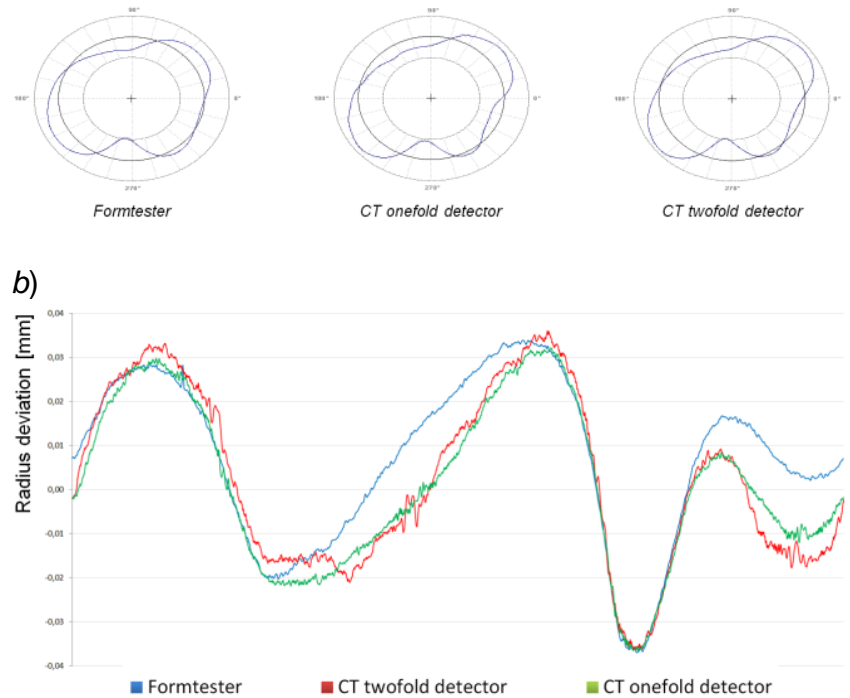

Fig. 3. Results of the outer contour of the sleeve for the crosssection $80 \mathrm{~mm}$ from the top: a) the outline of roundness deviation for the three measurement methods, b) the assembly of the measured profiles presented as the radius deviation as a function of the angle of rotation

a)
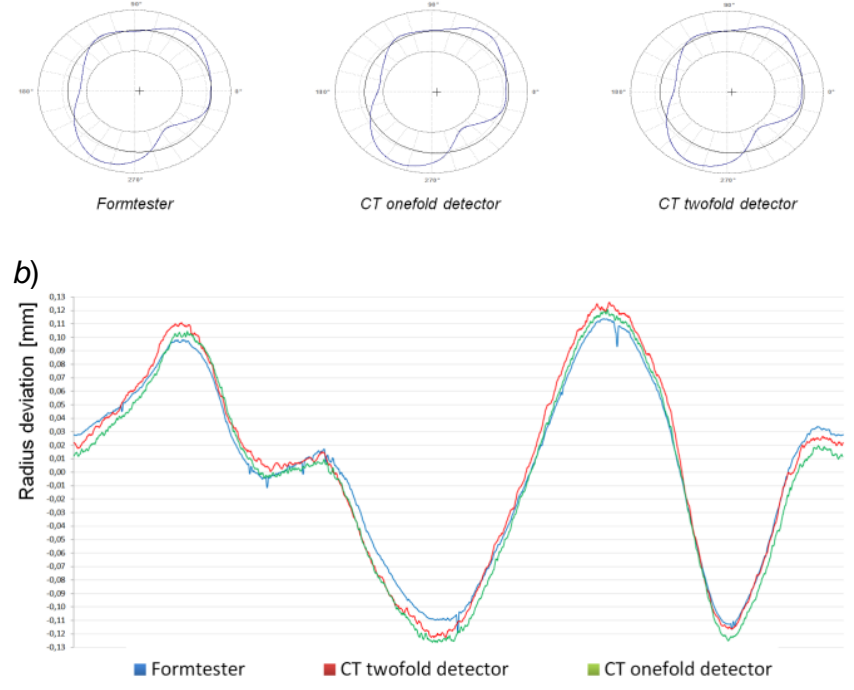

Fig. 4. Results of the internal contour of the sleeve for the cross-section $80 \mathrm{~mm}$ from the top: a) the outline of the roundness deviation for the three measurement methods, b) the assembly of the measured profiles presented as the radius deviation as a function of the angle of rotation

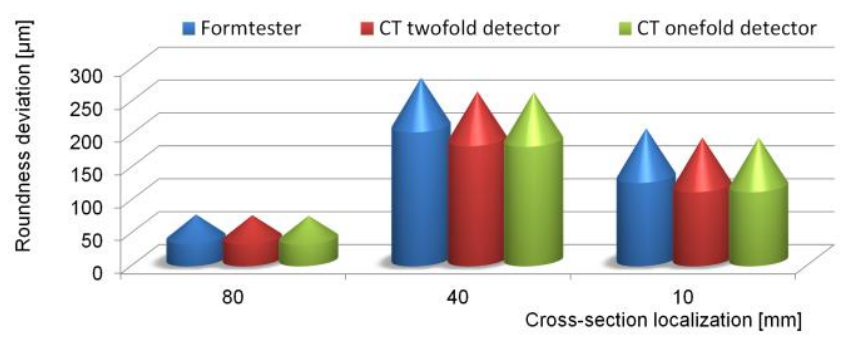

Fig. 5. Roundness deviation of outer cross-sections obtained as a result of measurement using roundness-meter and computer tomography 


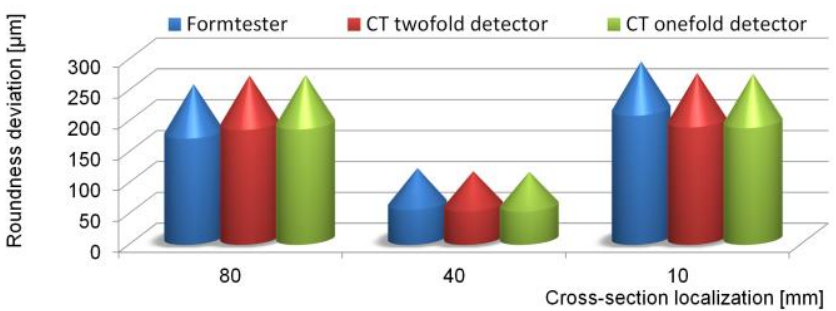

Fig. 6. Roundness deviation of outer cross-sections obtained as a result of measurement using roundness-meter and computer tomography

Fig. 5 and fig. 6 present collective results for outer and inner profiles measured in three cross-sections. It can be seen differences in the obtained values, but they do not exceed $5 \%$ of the deviation value for the considered outline. As mentioned, the aluminum alloy has been modified for research purposes. This is the reason for significant differences in the value and form of roundness deviation in individual cross-sections as well as inner and outer profiles.

\section{Conclusions}

The possibilities of using a computer tomograph to assess deviation of roundness were presented. Comparing the values shown in fig. 3 and fig. 4 , it can be noticed that differences between the values obtained on the roundness-meter and CT are similar in value. Therefore, in the case of an outer cross-section (fig. 3), they are much more visible than for the inner crosssection, as they refer to three times larger deviations of the profile.

Due to the uncertainty of measurement, specialized instruments are still much more accurate. However, computer tomographs allow to obtain a lot of information during a single measurement, including for measuring the shape deviations of surfaces that are not available in a closed hole.

The presented research results, were funded with grants for education allocated by the Ministry of Science and Higher Education in Poland No. 02/22/DSPB/1387.

\section{REFERENCES}

1. Adamczak S. „Pomiary geometryczne powierzchni”. Warszawa: WNT, 2008.

2. Ratajczyk E., Woźniak A. „Współrzędnościowe systemy pomiarowe". Warszawa: WPW, 2016.

3. Kruth J.-P., Bartscher M., Carmignato S., Schmitt R., De Chiffre L., Weckenmann A. "Computed tomography for dimensional metrology". CIRP Annals. 61, 2 (2011).

4. Ratajczyk E. „Tomografia komputerowa CT w zastosowaniach przemysłowych. Cz. I. Idea pomiarów, główne zespoły i ich funkcje". Mechanik. 2 (2011): pages 111-117.

5. Ratajczyk E. „Tomografia komputerowa CT w zastosowaniach przemysłowych". Mechanik. 2 (2011): s. 112-117; 3 (2011): s. 226-231; 4 (2011): pages 326-331.

6. Gapiński B., Wieczorowski M., Grzelka M., Arroyo Alonso P., Bermúdez Tomé A. "The application of micro computed tomography to assess quality of parts manufactured by means of rapid prototyping". Polimery. 62 (2017): pages 53-59.

7. Maszybrocka J., Stwora A., Gapiński B., Skrabalak G., Karolus M. "Morphology and surface topography of Ti6Al4V lattice structure fabricated by selective laser sintering". Bulletin of the Polish Academy of Sciences. Technical Sciences. 65, 1 (2017): pages $85-92$. 